\title{
Zero Emission Power Plant
}

\author{
Ramireddy Vinod ${ }^{1}$, M.Avinash Reddy ${ }^{2}$ \\ ${ }^{1,2}$ (Electrical and Electronics Engineering, JNTUH Karimnagar, India)
}

\begin{abstract}
India is the world's fourth largest economy and has a fast growing energy market. India's current power capacity is $30 \%$ short of demand. Coal and petroleum are the primary sources of energy. High ash content in Indian coal and inefficient combustion technologies contribute to India's emission of air particulate matter and other trace gases, including gases that are responsible for the greenhouse effect.

Climate change is one of the most serious single challenges faced by humankind today. Probably one of the greatest impacts in reducing CO2 emissions will be made by the introduction of Zero Emission Fossil Fuel Power Plants including carbon dioxide capture and storage.

$\mathrm{CO}_{2}$ is the main greenhouse gas due to the very high overall amount emitted by human activities and about one third of the overall human $\mathrm{CO}_{2}$ emissions are produced by the power generation sector.

The zero-emission power plant is no longer a fantasy. Filters are becoming increasingly sophisticated; removing dust and other harmful substances from exhaust Gases. And in the future, new power generation technologies should prevent Emissions of carbon dioxide getting into the atmosphere. Enhanced measurement Methods and more efficient power distribution are also helping to ensure cleaner air.
\end{abstract}

Keywords: Syngas, oxyfuel combustion, IGCC, co2 capture technologies, SOFC-GT

\section{Introduction}

The rising population and changes in lifestyles consistent with rapid economic growth have accelerated the energy demand. Although we are searching for renewable energy sources, our main aim is to produce the huge amount of power to meet the energy demand. So, for such amount of power generation, thermal power plants are major contribution. According to the National Thermal Power Corporation, coal is used for approximately $62.3 \%$ of India's electric power generation. The emissions from thermal power plant are major concern. It leads to global warming. So, in order to reduce those emissions and to increase the plant efficiency, there are certain methods of capturing and sequestering to reduce emissions.

\section{Integrated Gasification Combined Cycle power plant (IGCC):}

The Oxy-blown power plants are more compatible than our conventional power plants regarding on emission levels. Among them Integrated Gasification combined Cycle power plant is the best one. An Integrated Gasification Combined Cycle plant (IGCC) lends itself to $\mathrm{CO} 2$ separation, with hydrogen as a byproduct, and efficiencies of power production up to $55 \%$.

Integrated Gasification Combined Cycle (IGCC) plants are already in operation. Here, a fuel such as coal is converted, with the addition of oxygen, into synthesis gas [Gasification]. Syngas is the primary fuel for IGCC applications. Natural gas is used for start up and as a backup fuel. During the start up process at $30 \%$ load, the gas turbine is transitioned to syngas and taken to base load and mainly carbon monoxide and hydrogen. The gasification process can produce syngas from high-sulfur coal, heavy petroleum residues and biomass. The plant is called integrated because its syngas is produced in a gasification unit in the plant which has been optimized for the plant's combined cycle. In this example the syngas produced is used as fuel in a gas turbine which produces electrical power. To improve the overall process efficiency heat is recovered from both the gasification process and also the gas turbine exhaust in 'Waste Heat Boilers' producing steam. This steam is then used in steam turbines to produce additional electrical power.

The main feature is that instead of using oxygen and nitrogen to gasify coal, they use oxygen and $\mathrm{CO}_{2}$. The main advantage is that it is possible to improve the performance of cold gas efficiency and to reduce the unburned carbon (char).

- proven lowest NOx, SOx, particulate matter and lower hazardous air pollutants,

- proven mercury and carbon dioxide removal,

- lower water usage, lower solids production

- sulfur and non-leachable slag by-products

In an IGCC plant, $\mathrm{CO} 2$ can be separated during the synthesis gas preparation stage. However, separation compression and storage of the gas reduces the efficiency by about 12 percentage points. IGCC 
plants can also be fed biomass or wastes from the chemical industry such as asphalt and even car tires. IGCC was one of the future projects of APGENCO to be installed in Dr.N.T.T.P.S, Vijayawada.

\section{Mercury Emissions:}

- IGCC is essentially the only coal technology that can effectively remove mercury from the environment.

- Carbon beds have demonstrated 99.9\% mercury removal from syngas (post "gas-clean-up").

- Carbon beds are less expensive and produce vastly smaller volumes of solid waste than activated carbon injection at PC plant.

\section{Carbon Capture and Reduction Techniques}

Before carbon dioxide (CO2) gas can be sequestered from power plants and other point sources, it must be captured as a relatively pure gas. $\mathrm{CO} 2$ is routinely separated and captured as a by-product from industrial processes such as synthetic ammonia production, $\mathrm{H} 2$ production, and limestone calcinations.

There are three technology routes to capturing $\mathrm{CO} 2$ : pre-combustion, post-combustion and oxyfuel combustion. Post-combustion and oxyfuel combustion technologies that can be retrofitted to today's coal plants. Both technologies are feasible, safe and have the potential to be cost-effective. The challenge lies in developing the processes so that they can be deployed economically on a large scale.

\section{CO2 Capture Options:}

$\mathrm{CO} 2$ capture involves the separation of $\mathrm{CO} 2$ from combustion gases and compressing it so that it is suitable for safe transport and storage. There are three basic capture systems to isolate $\mathrm{CO} 2$ from the combustion process: post-combustion separation, oxy-fuel firing, and pre-combustion separation.

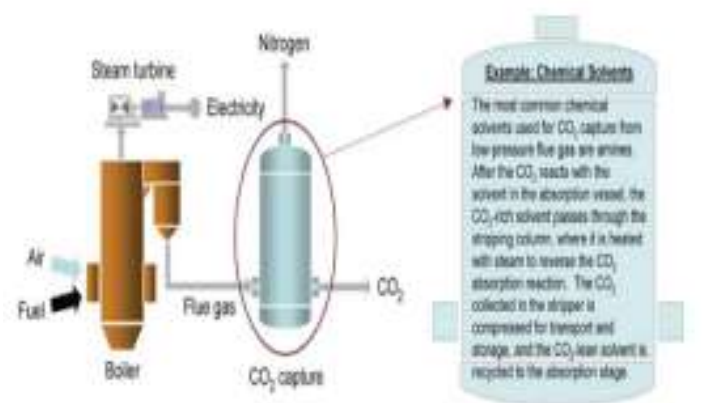

Figure 1:Post-Combustion Capture Using Solvents

\section{Post-combustion Capture:}

In this process, the $\mathrm{CO} 2$ is separated from the flue gases after combustion has taken place. Instead of being discharged directly to the atmosphere, the flue gas is passed through an absorbent or a selective membrane, which separates most of the $\mathrm{CO} 2$. The $\mathrm{CO} 2$, previously compressed, is fed to a storage reservoir and the remaining flue gas is discharged into the atmosphere.

\section{Advantages}

- High efficiency capture of $\mathrm{CO} 2$ and low heat of reaction.

- Low cost reagent.

- No degradation during absorption regeneration.

- Tolerance to oxygen and contaminations in flue gas.

\section{Pre-combustion Capture:}

Pre-combustion capture involves reacting the fuel with oxygen or air, and possibly also with steam, to produce a 'synthesis gas (syngas)' or 'fuel gas', composed mainly of carbon monoxide and hydrogen. The carbon monoxide is then reacted with steam in a catalytic reactor, called a shift converter, to give $\mathrm{CO} 2$ and more hydrogen. Next, the $\mathrm{CO} 2$ is separated, usually by a physical or chemical absorption process, resulting in a hydrogen-rich fuel which can be used in many applications, such as boilers, furnaces, gas turbines, engines and fuel cells. Pre-combustion capture of $\mathrm{CO} 2$ has to be part of the IGCC. This will be the future of fossil fuel power.

\section{Oxy-fuel Firing:}

In oxy-fuel combustion, nearly pure oxygen is used for combustion instead of air, resulting in a flue gas that is mainly $\mathrm{CO} 2$ and $\mathrm{H} 2 \mathrm{O}$. This simplifies the separation process as the water vapour can readily be condensed to liquid, leaving the $\mathrm{CO} 2$ for subsequent treatment. 
Advantages

- $\quad$ Large quantity of $\mathrm{O} 2$ required

- $\mathrm{CO} 2$ separation with no use of chemicals

- Smaller boiler and flue gas volume reduction (Low NOx)

\section{Carbon Control Technologies for Existing Plants}

The several innovative schemes that could significantly reduce $\mathrm{CO} 2$ capture costs, compared to conventional processes. These include:

- Oxyfuel Combustion processes use oxygen rather than air for combustion. The oxy-fuel cycles are a promising technology. The combustion with pure oxygen leads to a working fluid consisting mainly of steam and $\mathrm{CO} 2$, which allows an easy and cost-effective $\mathrm{CO} 2$ separation by steam condensation. Further advantages are the great variety of fuels which can be used (natural gas, syngas from coal or biomass gasification, etc.) and the low NOx generation, since nitrogen is only introduced by fuel bound nitrogen or as a residue in the oxygen to the combustion chamber. The generated NOx as well as other gases are removed together with $\mathrm{CO} 2$, so that no pollutants are emitted to atmosphere. This produces exhaust gas that is mainly water vapor and $\mathrm{CO} 2$. The exhaust gas has a relatively high $\mathrm{CO} 2$ concentration (greater than 80percent by volume). Oxyfuel combustion represents an opportunity to improve the economics of $\mathrm{CO} 2$ capture.

- Solvents and Sorbents for CO2 separation from flue gas (both physical and chemical) can be further enhanced to reduce cost, improve reaction rates and regeneration loads, and eliminate contamination from other pollutants. This includes technologies such as aqueous ammonia, advanced amines, ionic liquids, metal organic frameworks, and amine-enriched sorbents.

- Advanced Membranes for both oxygen-separation and CO2 capture are key enabling technologies. This effort will evaluate needs for advanced membranes applicable to pulverized coal systems and other conventional combustion systems that will minimize the cost and efficiency losses for CO2 separation.

- Chemical Looping processes that prevent direct contact of air and fuel offer the ability to produce a relatively pure stream of $\mathrm{CO} 2$ that does not need to be separated from flue gas. Technical challenges remain in key areas such as solids handling and oxygen carrier capacity, reactivity, and attrition.

Economic studies indicate that carbon capture will add over 30 percent to the cost of electricity for new integrated gasification combined cycle (IGCC) units and over 80 percent to the cost of electricity if retrofitted to existing pulverized coal (PC) units.

\section{CO2 storage and use}

Once captured and transported, most $\mathrm{CO} 2$ will be stored in geological reservoirs. The most of the countries are interested in a number of such reservoirs, including depleted and disused oil and gas fields, deep saline aquifers and deep un-mined coal seams or in the form of mineral carbonates.

\section{CO2 Storage Options:}

Depleted Oil and Gas Fields: These present a significant possibility for $\mathrm{CO} 2$ storage, with European capacities estimated at 14.5 billion tonnes offshore and 13.1 billion tonnes.

\section{Enhanced Oil (and Gas) Recovery:}

As an intermediate step, there is scope for injecting $\mathrm{CO} 2$ into mature fields to improve the recovery of oil (and gas) through Enhanced Oil Recovery (EOR), increasing production by $4-20 \%$.

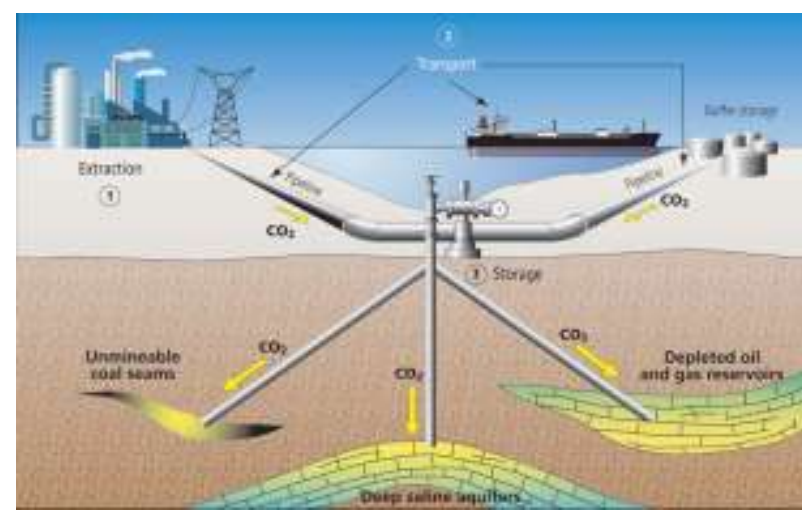

Figure 2:CO2 storage 
Saline aquifers: These have by far the greatest potential for storing $\mathrm{CO} 2$, globally as well as in Europe. Such aquifers are sedimentary rocks (usually sandstone and less frequently limestone or other rocks), which are porous enough to store great volumes of $\mathrm{CO} 2$ and permeable enough to allow the flow of fluids.

Storage of $\mathrm{CO} 2$ will take place at depths below some 7-800 meters where $\mathrm{CO} 2$ behaves as a fluid, and where the pores of the sediments are filled with salt water. Un-mineable coal seams: These offer another opportunity to store $\mathrm{CO} 2$ at a low net cost. In Enhanced Coal Bed Methane (ECBM) projects if a production well is opened, the coal adsorbs CO2 and N2 and methane is displaced, enhancing its production. While this approach is still in its early stages and needs more research, it is considered a promising concept due to the added value of the produced methane

Detailed knowledge and understanding is needed as to where and how $\mathrm{CO} 2$ can be stored. This understanding must include, for example, geographical locations, capacities, future behaviour in reservoirs, and associated risks, together with both national and international legal constraints. Attention must be given to the development of a monitoring methodology capable of building trust and confidence amongst citizens living in the vicinity of storage sites.

\section{SOFC-GT}

An SOFC-GT system is one which comprises a solid oxide fuel cell combined with a gas turbine. Further combination of the SOFC-GT in a combined heat and power plant also has the potential to yield even higher thermal efficiencies in some cases. In these plant SOFC is using as a replacement to combustor near gas turbine. It will generate electrical power at greater than $45 \%$ electrical efficiency. Within the SOFC module the desulfurized fuel is utilized electrochemically and oxidized below the temperature for NOx generation. Therefore NOx and SOx emissions for the SOFC power generation system are near negligible. The byproducts of the power generation from hydrocarbon fuels that are released into the environment are $\mathrm{CO} 2$ and water vapor. The development of methods to capture and sequester the $\mathrm{CO}$, resulting in a Zero Emission power generation system.

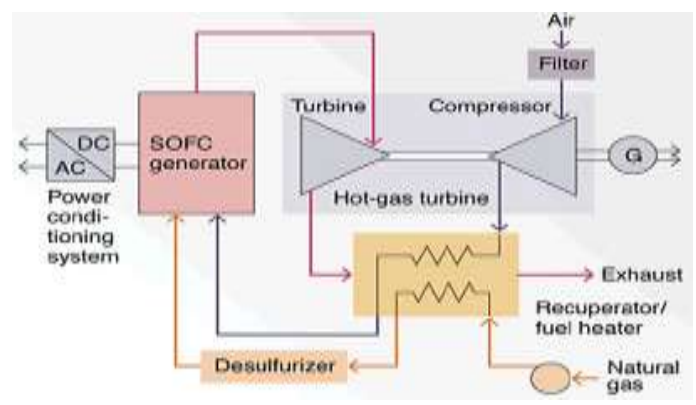

Figure 3 SOFC_GT

\section{MERITS}

- These are compact, lower cost equipment

- It has greater cycle efficiencies with advanced turbines.

- Complete carbon capture results the Zero emission(ultra low emission)

- The required amount of thermal energy is been supplied for desalination of water.

- Zero Emission Power Plant has "triple benefit".

- Carbon dioxide is captured and used for another application.

- Zero Emission power generated.

- Additional oil is produced from existing wells.

\section{DEMERITS}

- The largest disadvantage is the high operating temperature which results in longer start-up times and mechanical and chemical compatibility issues.

- Fuelling fuel cells is still a problem since the production, transportation, distribution and storage of hydrogen is difficult.

- The cost of $\mathrm{CO} 2$ captures using current technology, of carbon - much too high for carbon emissions reduction applications. 


\section{Conclusion}

In present scenario, combustion of fuels is at the heart of today's power generating system. It leads to the emission of green house gases which causes Global warming. Among these gases, $\mathrm{CO}_{2}$ constitutes the major proportion. The development of methods to capture and sequester the $\mathrm{CO} 2$, results in a Zero Emission power generation system and hence the overall performance and efficiency of a thermal power plant increases. Ultimately, the cost of installation, maintenance remains challenging in developing countries like India, but in developed countries like USA, Russia, and Germany are already using this technology.

\section{References}

[1] A Vision for Zero Emission Fossil Fuel Power Plants.pdf

[2] CO2Reduction by Development of High Efficient Coal-Fired Power Generation in Japan.pdf

[3] http://www.power.alstom.com/nox-emission-reduction.htm

[4] Solid Oxide Fuel Cell Hybrids: Challenges \& Benefits.pdf by GE Hybrid Power Generation Systems

[5] http://www.eee.columbia.edu/electricity/ZERO\%20EMISSION/Advanced\%20Zero\%20Emission\%20Power\%20Plant\%20Design.h tm

[6] Zero emission power plants 03 zer.pdf

[7] A new approach to co2 capturing technologies http://www.co2capture.com 